\title{
PLANETA ARTE: desenhando e compartilhando arte através de um ambiente virtual de aprendizagem
}

Prof. ${ }^{\text {a Dr. }}{ }^{\text {a }}$ Patrícia Alejandra Behar; NUTED/UFRGS; pbehar@terra.com.br Msc. Daisy Schneider; NUTED/UFRGS; daisy.schneider@gmail.com $\mathrm{Msc}^{\text {anda }}$. Caroline Bohrer do Amaral; NUTED/UFRGS;carolinebohrer82@yahoo.com.br $\mathrm{Msc}^{\text {anda }}$. Cristina Alba Wildt Torrezzan; NUTED/UFRGS crisaaw@ yahoo.com.br $\mathrm{Msc}^{\text {anda }}$. Daiane Mérici Almada Costa; NUTED/UFRGS; dai.almada@gmail.com Ana Paula Frozi de Castro e Souza; NUTED/UFRGS; nanafrozi@ yahoo.com.br

Ariane Nichele Cesar Longaray; NUTED/UFRGS; arianencl@ yahoo.com.br Bernardo Frederes Krämer Alcalde; NUTED/UFRGS; bernardoalcalde@ gmail.com Larissa Ebeling; NUTED/UFRGS; lari_ebe@yahoo.com.br

Resumo $O$ presente artigo apresenta o Planeta Arte, no que se refere ao contexto envolvido, fundamentação teórica, questões técnicas, pedagógicas e de design. Trata-se de uma funcionalidade do ambiente virtual de aprendizagem PLANETA ROODA, disponível em http://www.nuted.edu.ufrgs.br/planetarooda, o qual é destinado à Educação Infantil e Anos Iniciais.

Palavras-chave: desenho; ambiente virtual de aprendizagem;crianças; formação de professores.

\section{PLANET ART: designing and sharing art trough a virtual learning environment}

Abstract. This article aims to present the functionality Planet Art: context envolved, theoretical argumentation, technical, education and design issues. This functionality is available at PLANETA ROODA (http://www.nuted.edu.ufrgs.br/planetarooda), a virtual learning environment which has been developed for children and educators in school context.

Keywords: drawning; virtual enviroment of learning, kids, training teacher 


\section{INTRODUÇÃO}

As novas demandas do público infantil, no contexto escolar, referem-se a um outro tipo de infância decorrente do advento da informática: a ciberinfância. Essa diz respeito às crianças que nasceram em contato com a tecnologia e não conseguem imaginar o mundo sem estes recursos (Dornelles, 2005). Dessa forma, professores precisam confrontar suas práticas com formas diferentes de trabalhar com este público, valorizando a não-linearidade de conteúdos e o trabalho a partir da perspectiva do aluno.

Atualmente, os espaços infantis vêm sofrendo grandes mudanças, reconfigurados pelas noções de tempo e espaço diferenciadas pela relação com o ciberespaço. É o que Prensky (apud Mello \& Vicaria, 2007) definem como os nativos digitais. Pessoas que nasceram em contato com a tecnologia e não conseguem imaginar a comunicação antes dela, estabelecendo novas formas de relação com o mundo. Estas crianças estão nas escolas de hoje e exigem do professor outras práticas pedagógicas. Neste caso, está se falando do espaço virtual. As crianças começam a usar o computador e a internet precocemente, modificando o seu modo de pensar e a forma como elas aprendem na medida da sua interação com esses recursos. Logo, entende-se que a escola e os professores possuem dois desafios principais neste novo contexto: fazer da escola um lugar mais atraente para os alunos e fornecer a eles subsídios para uma compreensão verdadeira da sociedade da informação (Santos, 2006).

Dessa forma, entende-se que os Ambientes Virtuais de Aprendizagem (AVA), voltados para o público infantil podem responder a essas demandas atuais. De acordo com Behar et al (2007), os AVA são fundamentados por três aspectos interdependentes: epistemológicos (como o usuário constrói seu conhecimento), tecnológicos (suporte computacional/infra-estrutura) e metodológicos (prática pedagógica). Entende-se que, quando a atividade em grupo se desenvolve através de um AVA, o sujeito precisa criar estratégias para explorá-lo da melhor forma possível e efetivar trocas com seus colegas. No entanto, este processo é permeado pela sistematização dos recursos, o que agrega a disponibilização e apresentação das funcionalidades.

Assim, um AVA direcionado para crianças tem como pressuposto o suporte ao trabalho coletivo e à lógica de pensamento das crianças, remetendo à possibilidade de interação entre os participantes e ao crescimento cognitivo, a fim de atender as peculiaridades desse período do desenvolvimento humano. Um exemplo deste tipo de AVA é o Planeta ROODA, disponível em http://www.nuted.edu.ufrgs.br/planetarooda.

No presente artigo, dá-se ênfase à funcionalidade Planeta Arte, que tem como foco o desenvolvimento do desenho. Para tanto, é preciso compreender alguns aspectos teóricos que permeiam este assunto como, o desenho infantil, as tecnologias da informação e comunicação na Educação Infantil e Anos Iniciais, os recursos computacionais para crianças, uma descrição do Planeta ROODA e, finalmente, o Planeta Arte e um curso de extensão para professores em serviço.

\section{O DESENHO NA EDUCAÇÃO INFANTIL}

O PLANETA ROODA possui uma funcionalidade destinada à produção de desenhos, denominada de PLANETA ARTE. Para a construção desta, sentiu-se necessidade de estudar quais seriam os recursos mais interessantes para se trabalhar com o desenho através do computador. Para isso, a equipe do NUTED buscou fundamentação teórica na teoria de Luquet e Piaget em relação ao desenho infantil.

Segundo Luquet (1969), a criança desenha com o intuito de se divertir. O desenho para ela é um jogo como outros quaisquer. Este por sua vez, não é um substituto do 
objeto correspondente; é a obra da criança, produto e manifestação da sua atividade criadora, acompanhada de um igual prazer, quer o desenho reproduza um objeto presente ou ausente.

Pode-se considerar que o desenho infantil é uma importante ferramenta para o seu desenvolvimento, pois oferece, entre outras possibilidades o desenvolvimento da criatividade e o desenvolvimento da expressividade. $O$ desenho é um meio de comunicação tanto interpessoal, como intrapessoal. Por meio do desenho, a criança consegue expressar as suas emoções, necessidades e interesses de uma maneira não verbal, dado que, por vezes, a criança não sabe, não pode ou não quer expressá-las de maneira verbal. Nesta perspectiva, desenvolvimento do desenho merece destaque por sua importância no fazer artístico e na construção das demais linguagens. A criança utiliza o processo de imitação que decorre de suas experiências pessoais, que tem a interação da assimilação dos conteúdos, de formas e de figuras, por meio de representação. Com isso, desenvolve uma função importante no processo de ensino e de aprendizagem.

Dentro deste contexto, há grande interesse em verificar como as crianças da Educação Infantil aprendem pela expressão gráfica, em particular, do desenho. Nessa etapa, é muito utilizado o desenho como uma forma privilegiada de representação, na qual podem expressar suas idéias, situações do real e registrar informações. Geralmente, as respostas são as mais variadas, conforme o modo de pensar da criança, a sua formação em casa e na escola, como também de acordo com os materiais que têm contato.

O desenho infantil ou a representação gráfica é um instrumento importante para o desenvolvimento infantil. Segundo Piaget (1978), a criança inspira-se não no modelo objeto que tem diante dos olhos mas sim, na imagem que tem em seu espírito no momento em que desenha, ou seja, no modelo interno. Assim, o desenho é uma forma de representação que pode revelar o conteúdo da imagem mental da criança, podendo-se perceber se o objeto a ser representado necessita ou não estar presente para que a representação ocorra ou se o desenho é apenas uma tentativa de imitação.

\section{TECNOLOGIAS DA INFORMAÇÃO E COMUNICAÇÃO NA EDUCAÇÃO INFANTIL E ANOS INICIAIS DO ENSINO FUNDAMENTAL}

O PLANETA ROODA é destinado ao trabalho pedagógico com crianças no contexto escolar, como foi mencionado. A fim de entender melhor esse contexto é apresentado um breve panorama da situação das tecnologias da informação e comunicação (TIC) na Educação Infantil e anos iniciais. A sala de aula desta etapa do ensino configura-se como um espaço onde a criança tem suas primeiras experiências de interação com seus pares. Para tanto, faz-se importante uma relação pedagógica na qual professores e crianças estejam em constante comunicação e interação, de forma que o planejamento responda às curiosidades, necessidades e interesses da turma como um todo.

Nesse contexto, a sala de aula deve possibilitar um espaço de cooperação tanto entre professor-aluno, quanto entre os alunos. DeVries \& Zan (1998), colocam que a cooperação exige coordenação de pontos de vista e um ajuste progressivo na compreensão do outro em um intercâmbio de propostas e contra-propostas. Logo, o uso de ferramentas que permitem a interação da criança com seus pares, como também com os próprios recursos facilitam o desenvolvimento social, moral e intelectual. Isto ocorre por duas razões: a relação de igualdade que a criança terá em contato com os seus pares e a motivação da criança, em conseqüência desta interação, estabelecida através de trocas cognitivas, simbólicas e afetivas. 
Assim, uma das preocupações desta etapa da Educação Básica é proporcionar às crianças conhecimento do mundo. Este pode ser relativo ao seu mundo próximo, que abarca o próprio contexto da sua sala de atividades, o espaço exterior à escola, físico e comunitário ou, ainda, a um mundo mais distante que abarca o conhecimento e sensibilização a diferentes áreas científicas, como também o conhecimento de outras realidades, naturais, sociais ou culturais. Nesse paradigma, para Amante (2007), as tecnologias da informação e comunicação (TIC) podem proporcionar aos educadores e, às próprias crianças oportunidades únicas de acesso a pessoas, imagens, sons e informações muito diversificadas e dificilmente acessíveis de outro modo, que podem seguramente se constituir como poderosos recursos educacionais. Dessa forma, o uso da tecnologia na Educação Infantil permite que a criança busque respostas de forma rápida, a sua grande curiosidade. Abre-se, assim, um leque de conhecimentos que, integrado intencionalmente no conjunto do trabalho desenvolvido, pode contribuir para ampliar a compreensão do mundo e as representações dele.

Para tanto, o professor tem como uma das suas funções familiarizar a criança com a tecnologia, quando se faz necessário, além da orientação, da criação de contextos adequados e das condições para o desenvolvimento, tanto na construção de modelos estratégicos quanto na atribuição de sentido que conduza a uma aprendizagem significativa. A utilização das TIC pelos professores de Educação Infantil também exige novas propostas de planejamento pedagógico. Assim, a formação do educador tem como objetivo possibilitar a participação deste na organização de novos processos na sala de aula, ampliando suas experiências e proporcionando a reflexão sobre as infâncias.

\subsection{RECURSOS COMPUTACIONAIS PARA EDUCAÇÃO INFANTIL}

Os campos da história, da sociologia e da antropologia têm problematizado o papel ativo da criança na sociedade. Tais pesquisas vão de encontro à universalização da infância na modernidade, pois trazem novas compreensões sobre o significado de ser criança e de viver a infância. Assim, a criança passa a ser compreendida como alguém que pode estabelecer e produzir uma rede de práticas sociais, interagindo com outros atores sociais e com a produção de sua cultura (Schneider, 2007) dentro de um tipo de infância. De acordo com Dornelles (2005), está se vivendo uma crise da infância que, como as demais crises, resulta em novos modos de se ver e se tratar as práticas diárias com as crianças. A nova cultura na qual elas estão inseridas, os espaços que ocupam atualmente, produzem infâncias globalizadas em contato direto com o mundo. Esses espaços reconfiguram a infância contemporânea, produzindo a Ciberinfância, segundo essa autora. As crianças têm acesso à outras formas de imaginar, sentir, pensar e construir sua realidade infantil. Isso porque têm a possibilidade de conversar em tempo real, seja por e-mail, comunicadores instantâneos, seja por sites de relacionamento. Ao fazer o uso dessas possibilidades virtuais interativas, as crianças encontram novas formas de se sociabilizar e se produzir como sujeitos infantis hoje (Dornelles, 2007).

Nesta abordagem, a criança apropria-se do uso do computador, da mesma forma como conhece os objetos de seu mundo externo, através de descobertas. Logo, o computador pode ser explorado como um brinquedo, carregado de valores culturais e ativo, que responde à criança e permite novas conexões com o mundo. A apropriação dessa linguagem ocorre como um jogo de troca de significações entre a criança e a máquina, no qual a criança é capaz de interagir de forma autônoma. Na linguagem informática, os símbolos e ícones substituem a escrita, permitindo que a criança realize atividades sem fronteira na web. 
Nesta perspectiva, os jogos eletrônicos e os espaços digitais que as crianças ocupam no ciberespaço, contribuem para a construção do sentido de cooperação entre as crianças, favorecendo a constituição de comunidades virtuais de aprendizagem. Neste estudo, os espaços digitais da ciberinfância são entendidos como os recursos informáticos que permitem interação e comunicação entre crianças-objetos e outras crianças ou adultos. Ou seja, ferramentas informáticas que possibilitem a interação entre sujeito-objetos, como também entre os próprios sujeitos, formando um espaço virtual. Esse espaço virtual constitui o ciberespaço que permite a comunicação e produção coletiva, com uma cultura própria, a cibercultura, resultado da interação entre os sujeitos. Logo, o ambiente virtual de aprendizagem PLANETA ROODA pode ser considerado um destes espaços.

\section{PLANETA ROODA}

O Ambiente Virtual de Aprendizagem PLANETA ROODA, disponível em http://www.nuted.edu.ufrgs.br/planetarooda, tem como temática o espaço sideral, visto que é um tema freqüentemente levantado pelas crianças, pois desperta a curiosidade pelo mistério que o envolve, como também pela possível relação com o processo de conhecer. Foi desenvolvido a partir de um levantamento em sites e AVAs disponíveis na Internet para o público infantil em língua portuguesa, bem como por uma pesquisa desenvolvida com uma escola particular e com uma pública do município de Porto Alegre, Rio Grande do Sul (Schneider, 2007). Nesse estudo, baseado na Pesquisa Participante, os sujeitos contribuem ativamente. Dessa forma, foram realizadas entrevistas semi-estruturadas, segundo Delval (2002), partindo do Método Clínico, desenhos das crianças, registros em diário de campo, registros dos participantes no ambiente, curso de extensão para as professoras, como também projeto-piloto em uma das escolas participantes da pesquisa. Em todo o processo, houve uma escuta permanente sobre as colocações dos participantes. Além disso, foram realizadas reuniões de equipe para traçar os objetivos e analisar as contribuiçõos realizadas. A seguir, são apresentados os resultados desse estudo para a construção do PLANETA ROODA.

O desenvolvimento do AVA PLANETA ROODA, embora tenha uma perspectiva mais pedagógica, compreende também questões de programação que influenciam no seu uso e que são colocadas neste trabalho a título de informação. O ambiente foi desenvolvido como um software livre, com o intuito de permitir adaptações às necessidades das escolas. Por essa razão, o AVA foi construído com GNU/LINUX, linguagem de programação PHP, visando à utilização em diferentes navegadores e ao aperfeiçoamento constante, e possui licença GPL. As funcionalidades foram modeladas no padrão de linguagem UML.

Quanto ao aspecto pedagógico, o referido ambiente foi construído com a finalidade de ser um espaço que possibilite o trabalho coletivo e ativo de alunos e professores da Educação Infantil e do Ensino Fundamental na Internet pelo uso de suas funcionalidades, as quais podem potencializar a aprendizagem, os processos comunicacionais e o gerenciamento de turmas, conforme a prática do professor. Caracteriza-se por ser centrado no usuário e por possibilitar a personalização da interface gráfica e a avaliação processual. Assim, seus usuários (professores, monitores e alunos) podem interagir de várias maneiras no AVA: com outros usuários por meio das funcionalidades síncronas e assíncronas, dos/com materiais publicados, das/com produções e registros. Essa composição permite a realização de diferentes práticas pedagógicas. Desse modo, entende-se que é possível construir conhecimentos, pois a 
aprendizagem em AVAs com uma abordagem construtivista ocorre através dessas interações com os objetos de conhecimento.

Com uma postura voltada à cooperação e à interdisciplinaridade, podem ser compostos espaços que proporcionam a investigação e a multiplicidade de vozes, desafiando e envolvendo as crianças e professores. Da mesma forma, pretende-se contribuir, através das funcionalidades desse AVA, para a potencialização da expressão por meio da escrita e de imagens nas publicações de produções e de registros; das relações cooperativas e o enriquecimento das experiências realizadas no contexto escolar, apoiadas em um recurso digital. O PLANETA ROODA também possui recursos nos quais, tanto alunos, quanto professores podem ter um espaço reservado. Entretanto, como o ambiente não é um portal, não possui conteúdos específicos gerados pela sua equipe de desenvolvimento.

Este apresenta ferramentas de comunicação (Comunicador, Bate-papo e Fórum), para disponibilização de arquivos e trabalhos em grupo (Projetos), desenho (Planeta Arte), construção de jogos (Planeta Pergunta), perfil de usuário (Carteira), entre outras ferramentas que proporcionam a interação e o trabalho cooperativo, de acordo com a ação pedagógica do professor. O ambiente é de fácil navegação, pois utiliza símbolos, tais como uma borracha para apagar, um avião de papel para enviar, os quais são do cotidiano das crianças, nos botões de navegação. Dessa maneira, mesmo crianças não alfabetizadas podem utilizar o ambiente.

No presente artigo, será detalhada a funcionalidade Planeta Arte. Demais informações sobre o Planeta Rooda podem ser encontradas em Behar et al. (2007b).

\section{CONSTRUINDO O PLANETA ARTE}

O Planeta Arte e suas funcionalidades foram construídos utilizando as linguagens de programação web DHTML, JavaScript e PHP integradas com banco de dado MySQL. A técnica de comunicação, conhecida como AJAX, também se fez presente na elaboração de vários recursos deste objeto.

O cerne da aplicação é a tela de pintura, destinada à criação e edição de desenhos. Essa interface dispõe de recursos presentes na grande maioria dos softwares do gênero, tais como: ferramenta de desenho a mão livre, borracha, formas geométricas e ferramenta de texto. Essas são complementadas pelos carimbos, ou seja, pequenas imagens - pré-definidas pelo sistema ou criadas pelo usuário - que podem ser livremente inseridas na tela e aplicadas nos novos desenhos.

A tela de pintura foi implementada a partir de uma aplicação genérica de desenho em código aberto baseada em CANVAS. Esse é um objeto recentemente agregado ao HTML. Ele é exibido no navegador como um retângulo de dimensões flexíveis, permitindo representar várias imagens e gráficos, os quais podem ser modificados em tempo real através de métodos controlados por JavaScript. Embora seja um objeto relativamente recente - o que implica uma não uniformidade de implementação ou mesmo a não compatibilidade com alguns browsers -, o CANVAS provavelmente seja consolidado num futuro próximo, devido às possibilidades que ele oferece. Sua versatilidade permite desde a plotagem de gráficos atualizados em tempo real até a criação de cenários 3D.

As ferramentas da tela de desenho são implementadas como métodos de uma classe. Trata-se de rotinas de alto nível que tornam a programação da interface mais simples e clara, totalmente orientada a objetos e passível de integração com AJAX. Essa vantagem é justamente o que possibilita a implementação de certos recursos, como a ferramenta de texto. Apesar de parecer "instantâneo" ao usuário, o processo que ocorre 
desde a edição do texto até a sua inclusão na imagem é bastante complexo. Após o texto ser digitado, um script em PHP é chamado via AJAX. Essa rotina gera uma imagem temporária contendo o texto desejado que, através de outra manipulação de JavaScript, é finalmente inserido na tela de pintura.

Embora bastante apropriado para a finalidade descrita, o CANVAS tem mostrado algumas limitações. Por se tratar de, como já foi dito, um recurso novo, ele não é bem interpretado por alguns navegadores, como o Internet Explorer. Neste browser em especial - embora esteja disponível uma biblioteca que o torna compatível com o objeto - não é possível salvar os novos desenhos, nem editar os já existentes. Recomenda-se o Mozilla Firefox, versão 2.0 ou superior, para usufruir corretamente de todas as ferramentas que o Planeta Arte disponibiliza.

A falta de documentação é outro empecilho. Existem várias potencialidades do CANVAS que não podem ser plenamente exploradas por falta de documentação. Nesta categoria, encontram-se funcionalidades importantes como desfazer, copiar e colar.

Para versões futuras do Planeta Arte, buscar-se-á, em nível técnico, sanar essas restrições através do aprofundamento do estudo sobre o elemento CANVAS e da elaboração de bibliotecas que o tornem compatível com outros navegadores. Estuda-se, também, implementá-lo em Flash, o que resolveria de uma vez por todas os problemas relacionados à compatibilidade.

Para a elaboração da tela principal, onde serão realizados os desenhos, foram criados ícones que reportam a materiais normalmente utilizados na elaboração de desenhos analógicos, como lápis, borracha, caderno e giz de cera (figura 2). A adoção dessa metáfora facilita a interpretação desses ícones pelas crianças. As demais ferramentas e botões, como a linha reta, círculo e o disquete (salvar), seguem o padrão normalmente utilizado na maioria dos softwares gráficos disponibilizados na atualidade.

Outro fator importante e relacionado com a usabilidade do sistema é a disposição das ferramentas na interface. Organizou-se uma setorização funcional, de modo que as ferramentas de edição fiquem localizadas à esquerda, ferramentas de arquivamento (salvar, copiar) à direita e bônus (carimbos) na parte superior (figura 1). Desse modo, além de possibilitar que ícones de diferentes funções se distribuam em locais opostos (evitando possíveis enganos), disponibiliza-se a liberação do máximo de espaço para o quadro de desenhar.

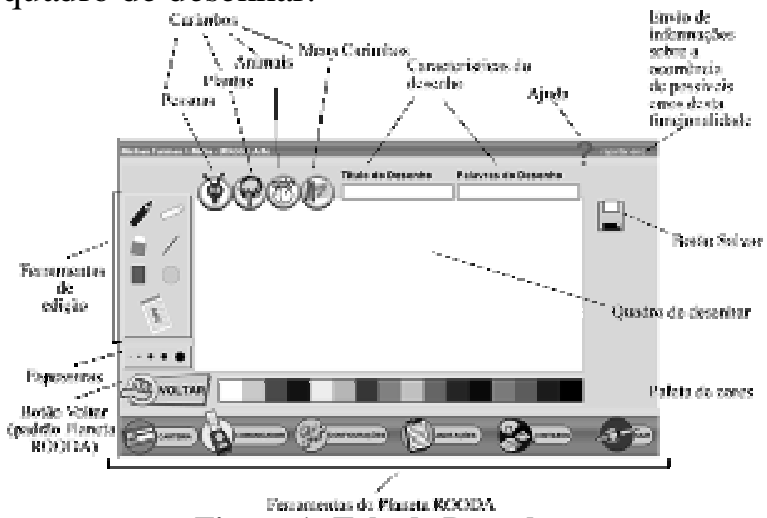

Figura 1: Tela de Desenhar

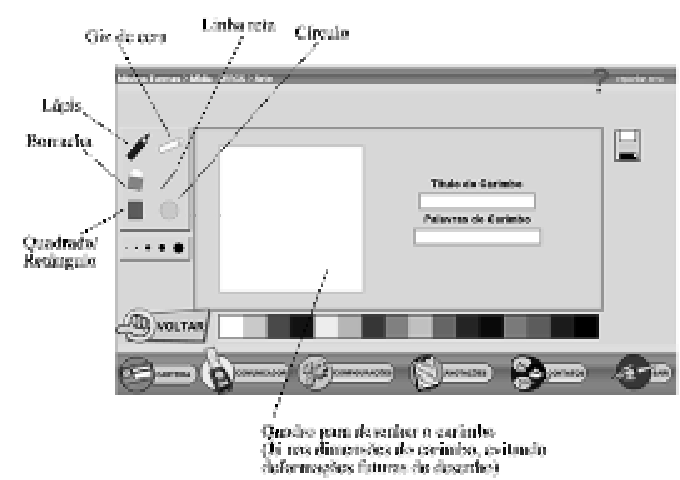

Figura 2: Tela de Desenhar Carimbo

Nas demais telas (secundárias) responsáveis pela administração dos desenhos elaborados, preocupou-se em propiciar ao usuário o maior número possível de acessos a partir de um número mínimo de ações. É o que pode ser visualizado nas figuras 3 a 8 . 


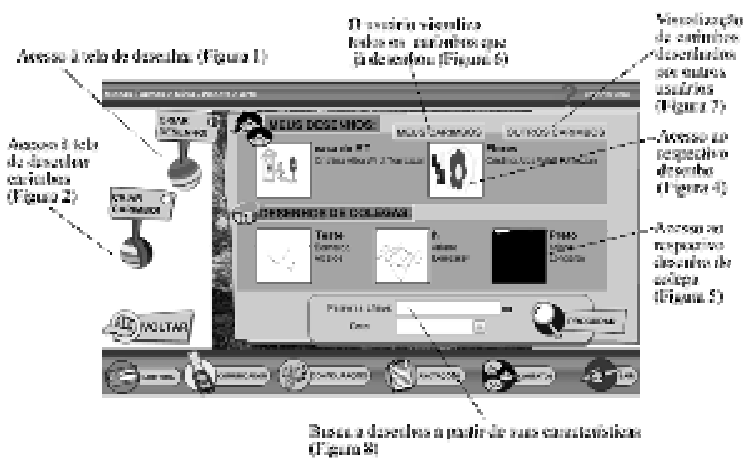

Figura 3: Tela inicial do Planeta Arte

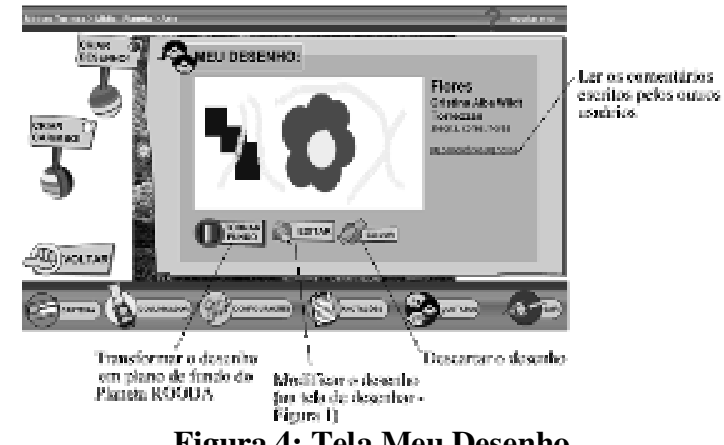

Figura 4: Tela Meu Desenho

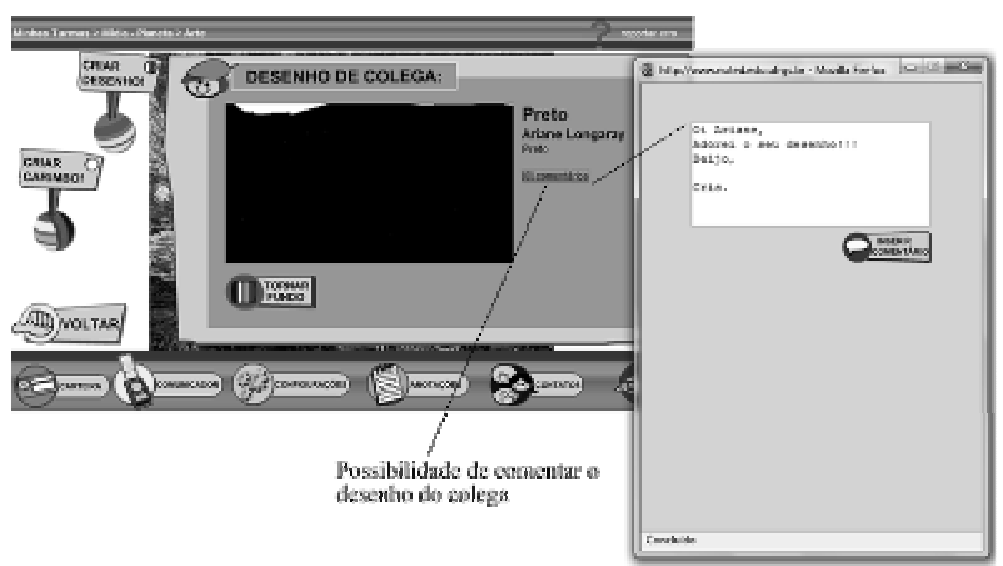

Figura 5: Tela Desenho De Colega
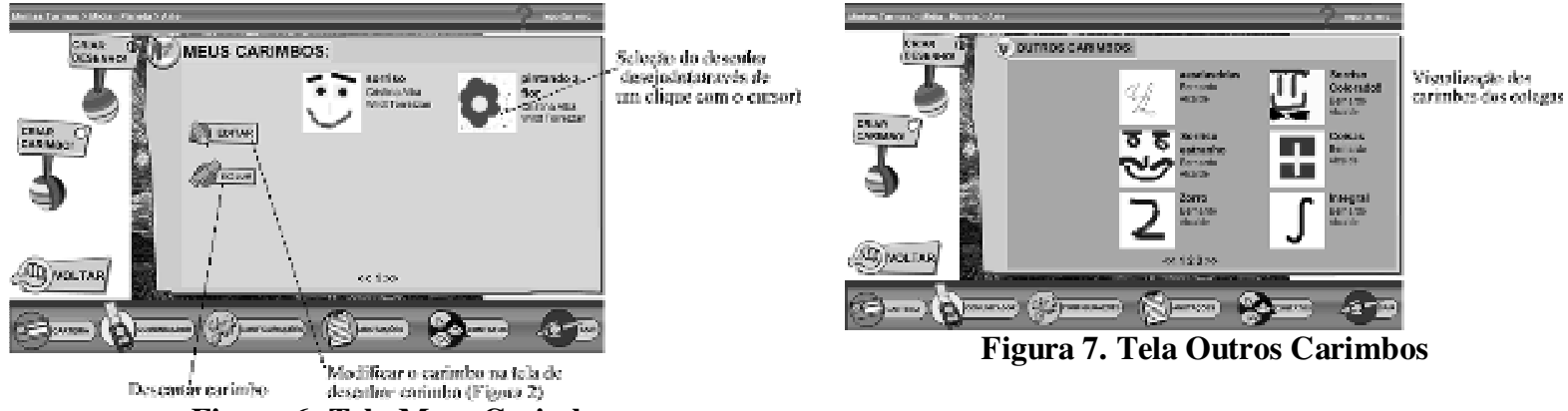

Figura 6: Tela Meus Carimbos

\section{Figura 7. Tela Outros Carimbos}



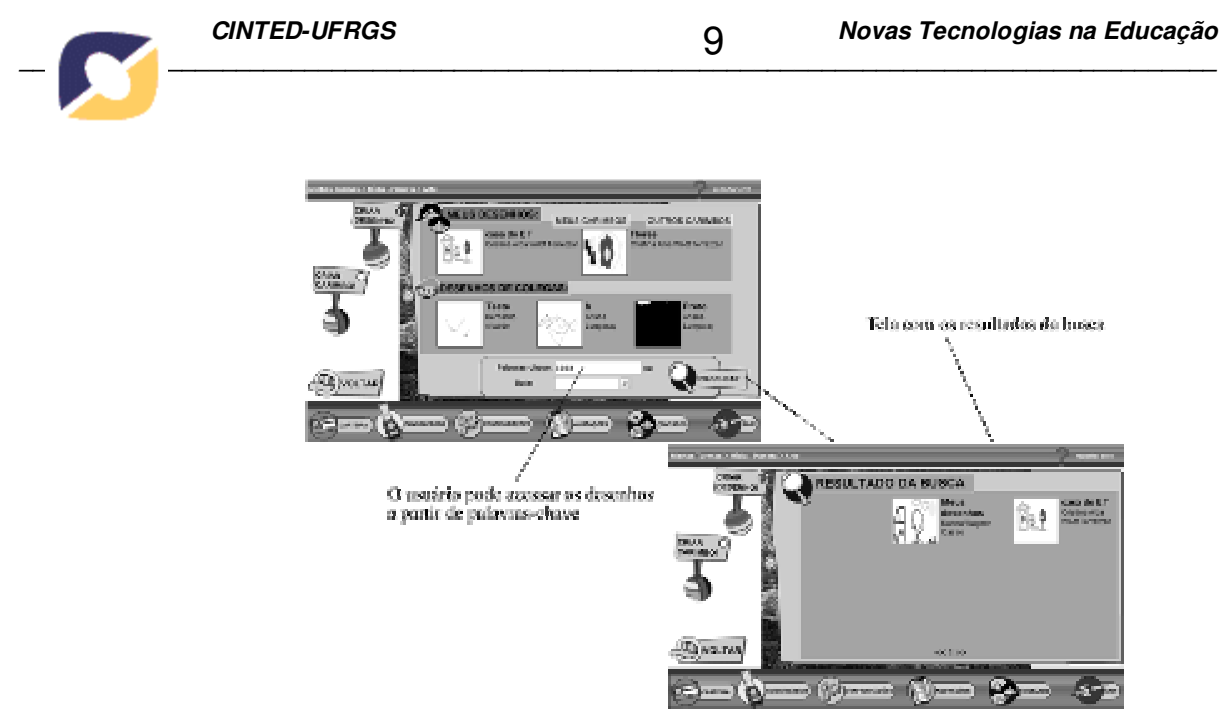

Figura 8. Acesso a desenhos através da busca

A construção do Planeta Arte objetivou a elaboração de interfaces que, através da sua interatividade e usabilidade, apoiassem a trajetória e o desenvolvimento das crianças, aplicando a tecnologia para possibilitar práticas pedagógicas além das propiciadas em sala de aula tradicional.

Dessa forma, as funcionalidades projetadas para o PLANETA ARTE são: 1) Estilo de Letras: o usuário terá a sua disposição alguns modelos de letras. 2) Caixa de texto: o usuário pode digitar pequenos textos no seu desenho. 3) Giz de cera: para colorir e desenhar. 4) Reta: traço retilíneo 5) Formas geométricas: quadrados, retângulos e círculos. 6) Painel de cores 7) Carimbos: imagens pré-definidas como flores, pessoas, objetos, animais, ou os carimbos criados pelo usuário. 8) Lápis: traços com efeito mão livre. 9) Borracha: apagar o desenho ou pequenos detalhes. 10) Papel de Parede: o desenho pode ser utilizado como papel de parede do AVA PLANETA ROODA. 11) Salvar: todos os desenhos poderão ser salvos no Planeta Arte quando for utilizado o navegador Firefox, de acordo com o que foi explicitado anteriormente acerca da programação. 12) Comentários: podem ser deixados comentários a respeito dos seus desenhos e de seus colegas. Cabe salientar também que o usuário tem 5 opções de espessura e largura para escolher antes de desenhar ou apagar os desenhos e/ou carimbos feitos.

\section{FORMANDO PROFESSORES PARA O USO DO PLANETA ARTE}

O Planeta Arte encontra-se atualmente em fase de testes. Para tanto, foi realizado em 2008/1 um curso de extensão a fim de avaliar a sua performance, detectar possíveis bugs e iniciar a divulgação do ambiente. Foram abordados os seguintes temas: (1) Ambientes Virtuais de Aprendizagem (AVA)'s, mais especificamente, o PLANETA ROODA; (2) Formação do Símbolo na criança de acordo com a teoria de Jean Piaget; e (3) Desenho Infantil como forma de representação. Foram oportunizados momentos de reflexão e construção do conhecimento acerca do uso de AVA's como o PLANETA ROODA e, de forma mais detalhada, o Planeta Arte, focado para a Educação Infantil e Anos Iniciais. No curso, foi dada ênfase ao desenho infantil, do ponto de vista do desenvolvimento da função simbólica na criança (Piaget, 1978), complementando com as idéias trazidas por Luquet (1969).

As aulas foram ministradas com o suporte do PLANETA ROODA e utilizadas as funcionalidades: Fórum e Bate-papo (ambos para interação entre todo o grupo), Diário (para reflexões das alunas sobre seu processo de aprendizagem no curso), Projetos (trabalhos em grupo e publicação de arquivos), Biblioteca (publicação das aulas e de 
leituras complementares) e Contatos (comunicação por e-mail). O AVA possibilitou um registro das discussões entre os participantes do curso e a familiarização com este espaço digital. A escolha do PLANETA ROODA foi, justamente, com o intuito de que, após o curso, os professores pudessem utilizar este recurso em suas aulas e o divulgassem em suas escolas.

A coleta de dados constituiu-se dos registros no AVA das discussões e reflexões dos professore, do diário de campo acerca das questões mais importantes de cada encontro e as observações participantes junto à turma. $\mathrm{O}$ objetivo central desta etapa da pesquisa visou discutir e refletir sobre propostas de planejamento pedagógico que contextualizassem o uso do Planeta Arte em instituições de ensino de forma significativa. Como resultado parcial desta experiência, obteve-se o engajamento por parte de professores em sua aprendizagem, participando do curso com autonomia e adquirindo uma postura crítica frente ao uso da informática na educação e, especificamente, do Planeta Arte como recurso para o desenho. Esta pesquisa permitiu à equipe desenvolvedora vislumbrar a possibilidade de trabalhar a função simbólica, por meio do Planeta Arte, com atividades lúdicas e interação/comunicação entre os indivíduos.

Os aspectos técnicos da ferramenta também foram analisados. Dessa forma, foi possível corrigir erros nos sistema, bem como coletar sugestões para o aperfeiçoamento do Planeta Arte que já estão sendo implementadas.

\section{CONSIDERAÇÕES FINAIS}

O presente estudo mostra uma parte de um projeto de pesquisa ${ }^{1}$ que se propõe a desenvolver recursos computacionais para a Educação Infantil e Anos Iniciais, a serem disponibilizados em instituições educacionais. Para isso, são desenvolvidos cursos de extensão a fim de formar professores e apoiar suas práticas pedagógicas nestes novos espaços virtuais. $\mathrm{O}$ curso de extensão apresentado permitiu a transformação do meio e das práticas dos sujeitos envolvidos, respondendo ao caráter educacional que embasou sua metodologia. Constatou-se que não basta apenas tornar o uso do computador acessível para os alunos, é preciso vislumbrar as possibilidades que oferece, explorando-as adequadamente, integrando-as ao processo de ensino-aprendizagem e, principalmente, engajando os professores neste novo contexto educacional. Nesta perspectiva, entende-se que é de extrema importância a integração dos trabalhos desenvolvidos no meio acadêmico com as escolas, a fim de mostrar novos caminhos a serem trilhados com a introdução das tecnologias da informação e comunicação na prática pedagógica.

\section{REFERÊNCIAS BIBLIOGRÁFICAS}

AMANTE, L. As TIC na Escola e no Jardim de Infância: motivos e factores para a sua integração. Sísifo /Revista de Ciências da Educação, Lisboa. n. ${ }^{\circ}$ 3, p. 51-64, mai./ago. 2007. Disponível em: <http://sisifo.fpce.ul.pt/pdfs/\%20N\%FAmero3.pdf>. Acesso em: 15 nov. 2007.

BEHAR, P. A.; LEITE, S. M.; BORDINI, S.; SOUZA, L. B.; SIQUEIRA, L. G. Avaliação de Ambientes Virtuais de Aprendizagem: o caso do ROODA na UFRGS. Revista Avances en Sistemas e Informática. Medellín. v. 4, p. 81-100, 2007 a.

BEHAR, P. A. ; SCHNEIDER, Daisy; AMARAL, Caroline Boher ; MEIRELLES, Silvia . Um ambiente virtual de aprendizagem para crianças: Planeta ROODA. In: International

\footnotetext{
${ }^{1}$ Financiado pelo Cnpq - Conselho Nacional de Desenvolvimento Científico e Tecnológico V. 6 № 1, Julho, 2008
} 
Conference - Interactive Computer Aided Blended Learning, 2007, Florianópolis. Anais do.. CEFET : Kassel University Press, 2007b. v. 1.

DELVAL, J. (2002). Introdução à prática do método clínico : descobrindo o pensamento das crianças (F. Murad, Trad.). Porto Alegre: Artmed.

DeVRIES, R.; ZAN, B. A ética na educação infantil: o ambiente sócio-moral na escola. Porto Alegre: ARTMED, 1998.

DORNELLES, L. V. Infâncias que nos Escapam: da criança na rua à criança cyber. Petrópolis, RJ: Vozes, 2005.

LUQUET, G.H. O desenho infantil. Porto: Livraria Civilização, 1969.

MELLO, K.; VICARIA, L. Os filhos da era digital. Revista Época, 10 de set. 2007. p. 82-90.

PIAGET, Jean. A Formação do Símbolo na Criança: imitação, jogo e sonho, imagem e representação. 3. ed. Rio de Janeiro: Zahar, 1978.

SANTOS, B. A. Ciberleitura: o contribucto das TIC para a leitura no $1^{\circ}$ ciclo do ensino básico. Porto: Profedições, 2007.

SCHNEIDER, D. PLANETA ROODA: desenvolvendo arquiteturas pedagógicas para Educação Infantil e Anos Iniciais do Ensino Fundamental. Porto Alegre: PPGEDU/UFRGS, 2007. 138p. Dissertação de Mestrado. 